In conclusion, we wish to thank our colleague Prof. E. M. McMillan for supplying part of the material for this article and for helping in its preparation.

${ }^{1}$ Fermi, E., Nature, 133, 757 and 898 (1934). Fermi, E., Amaldi, E. D'Agostino, O., Rasetti, F', and Segre, E., Proc. Roy. Soc., A, 146, 483 (1934). Amaldi, E., D'Agostino, O., Fermi, E., Pontecorvo, B., Rasetti, F., and Segrè, E., Proc. Roy. Soc., A, 149, 522 (1935). "Hahn, O., and Meitner, L., Naturwiss., 23, 37 and 230 (1935). Hahn, o., Meitner, L., and Strassmann, F., Ber. deutsch. chem. Ges., 70, 1374 (1937).

${ }^{3}$ Meitner, L., Hahn, O., and Strassmann, F., Z. Phys., 106 249 (1937). Hahn, O., and Strassmann, F., Naturwiss., 26, 755 (1938)

'Curie, I., and Savitch, P., C.R. Acad. Sci., Paris, 208, 906 and 1643 (1938); J. Phys., (7) 9, 355 (1938).

${ }^{5}$ Hahn, O., and Strassmann, F., Naturwiss., 27, 11, 89 and 163 (1939)

- Hahn, O., Meitner, L., and Strassmann, F., Ber. deutsch. chem. Ges. 69, 905 (1936)

${ }^{7}$ Joliot, F., J. Phys., (7) 10, 159 (1939).

${ }^{8}$ Anderson, H. L., Booth, E. T., Dunning, J. R., Fermi, E., Glasoe, G. N., and Slack, F. G., Phys. Rev., 55, 511 (1939).

- McMillan, E. M., Phys. Rev., 55, 510 (1939).

${ }^{10}$ Segrè, E., Phys. Rev., 55, 1104 (1939).

${ }^{11}$ McMillan, E. M., and Abelson, P. H., Phys, Rev., 57, 1185 (1940).

${ }^{12}$ Starke, K., Naturwiss., 30, 107 and 577 (1942).

${ }^{13}$ Strassmann, F., and Hahn, O., Naturwiss., 30, 256 (1942).

14 Seaborg, G. T., McMillan, E. M., Kennedy, J. W., and Wahl, A. C. Phys. Rev., 69, 366 (1946) ; Seaborg, G. T., Wahl, A. C., an

${ }^{25}$ For a discussion of the flrst suggestions concerning the possibility for military use of the isotope $94^{238}$ see H. D. Smyth, "Atomic Energy for Military Purposes" (Princeton University Press, 1945), Sections $1.58,3.17,4.24$ and 4.25 .

18 Kennedy, J. W., Seaborg, G. T., Segrè, E., and Wahl, A. C., Phys. Rev., 70, 555 (1946).

17 Seaborg, G. T., Science, 104, 379 (1946).

1s Nishina, Y., Yasaki, T., Ezoe, H., Kimura, K., and Ikawa, M., Phys. Rev., 57, 1182 (1940)

10 McMillan, E. M., Phys. Rev., 58, 178 (1940).

\section{THE ZOOLOGICAL SURVEY OF INDIA}

\section{By Prof. H. MUNRO FOX, F.R.S. Bedford College, London}

$\mathrm{T}$

HE Zoological Survey of India was founded in 1916. It derived from the Zoological Section of the Indian Museum. The latter was a descendant of the zoological portion of the Asiatic Society of Bengal. Annandale, a first-class naturalist and an authority on freshwater faunas, was the first director of the Survey. He had distinguished successors in Kemp, Sewell, and Prashad, and, when the last-named was lately called to be adviser on fisheries to the Government of India, in Dr. B. N. Chopra, the present acting director. Other members of the Survey who have achieved a high reputation are Dr. S. L. Hora, who for the past few years has been director of fisheries in the Province of Bengal, and Dr. H. S. Pruthi, recently selected to be director of the new Plant Pest Protection Bureau. From the beginning, however, the staff was small, and unhappily retrenchment in the early nineteen-thirties so much reduced it that the Survey was forced almost to abandon field work and to restrict itself to museum activities, thus cutting out its main purpose, namely, the animal survey of India. Indeed, the staff then became so small that even the proper care of the large and valuable collections became difficult.

The objects for which the Survey was founded were the following. First, it was to undertake faunistic studies so as to acquire all possible information on the geographical distribution of Indian animals ; secondly, to maintain and add to the national zoological collections started nearly a century and a half ago by the Asiatic Society of Bengal; thirdly, to maintain and develop the public exhibits in the Indian Museum; fourthly, to identify specimens as required by investigators in any part of the country; and fifthly, to advise the Government on zoological matters. It is clear that the Survey has the functions of the British Museum (Natural History) in London with the obligations of the field survey in addition. This is an immense task in a country of the size of India.

In zoology, as in all the sciences, investigators will go on making discoveries for their own sake, from purely scientific curiosity. This is how fundamental science advances. Some of these discoveries are from time to time made use of for human benefit ; no one can foretell which of them will be useful. The Zoological Survey of India functions in just this twofold way, and must continue to do so. Discoveries made by its staff in the field and in the laboratory may any of them be of inestimable value to India. This applies to medical zoology, which means animal pests and animals which transmit pests, to veterinary zoology, to agricultural science and forestry We may take one case a little more in detail, a case which is particularly important in view of the food shortage of to-day, namely, the fisheries. There is great need of developing and expanding the Indian fisheries, both marine and freshwater. More fish should be got out of the Indian seas, always taking care to avoid the danger of overfishing. Inland fishes could be more extensively and better grown in tanks. For all this, much knowledge is needed of the lives of the fishes. No doubt many of the necessary studies will be made in the universities, but the Survey must be the centralizing body, with its collections for the final precise identifications. It is seldom realized by non-biologists that all investigations must be based on the bedrock of accurate determination of the species of organism studied, and this is very much a specialist's responsibility. For development of the Indian fisheries there is also an urgent need for the establishment of at least one marine biological station, perhaps at Karachi where the fauna is good, and this should be closely linked to the Survey. It must be a research station such as that of Plymouth, with a permanent staff, adequate modern equipment, a research vessel, and a library.

In 1880 the Secretary of State for India commenced publication of the important series of monographs that bears the title of "The Fauna of British India". The early authors of these monographs were British, resident in India; for example, Dr. N. Annandale, Lieut.-Col. H. H. Godwin-Austen, Lieut.-Col. C. T. Bingham, W. T. Blandford, Lieut.-Col. Sir S. R. Christophers, Francis Day, Lieut.-Col. F. C. Frazer, G. F. Hampson, and Lieut.-Col. J. Stephenson. The first Indians to prepare monographs were $\mathrm{S}$. Maulik, then professor of zoology in the University of Calcutta, and Dr. B. L. Bhatia ; future volumes have been entrusted to Dr. Bhalerao, Dr. Chopra, Dr. Hora, Dr. Prashad and Dr. Sharif. With the introduction of self-government, the responsibility for the continuation of this series falls on the Government of India, and the editor of future volumes will be the director of the Zoological Survey of India : it is expected that many of the authors will be Indians, and the source to which one looks primarily for such experts is the Zoological Survey.

Last year Lieut.-Col. R. B. Seymour Sewell, formerly director of the Survey, returned to India at the invitation of the Government to submit proposals for the reconstruction and expansion of the Survey. His report was issued in November. 
It is a document of great importance to the future of the Survey and of India. Sewell makes it clear that an enlarged Survey is essential to the scientific and economic advancement of the country. There should be a very considerable expansion of the staff. Originally there were four officers, then seven, now only five. There should be at least two dozen in the near future, so that each branch of the animal kingdom shall have its expert. One of the new officers would be naturalist to the Marine Survey. This would be a revival of the surgeon-naturalist's post, so fruitful in the past in the deep-sea work of R.I.M.S. Investigator.

The immediate difficulty will be to fill these zoological posts. Early this year I was in India as a delegate to the Indian Science Congress and then visited a number of the universities. Some of the zoology departments were excellent, others less good; but in most of them the standard could well be raised. In Indian universities zoology has not been so much developed as some of the other sciences. This is, no doubt, a matter of tradition, hard to change. In addition there are in India very few field naturalists. This means that first-class personnel for expanding the Survey will not easily be found. Sewell has put forward a scheme for the training of young Indian zoological graduates of the universities for two years in the Survey and then for a year abroad.

The Survey, with all its valuable collections and library, was moved for safety during the War from Calcutta to temporary quarters at Benares. There it is to-day, quite inadequately housed. There is insufficient room either to tend or to consult the collections, and the building is liable to floods which have already damaged valuable books. The Survey has the best zoological library in India, probably in Asia. Sewell recommends the erection at New Delhi of a new home for the Survey in a fire-proof, air-conditioned building. Here it would be placed centrally for Government consultation, situated near other scientific institutes.

When India assumes independence she cannot afford to neglect the expansion of her Zoological Survey.

\section{NEW PHYSICO-CHEMICAL PHENO- MENA IN THE DEFORMATION AND MECHANICAL TREATMENT OF SOLIDS*}

\section{By P. REHBINDER}

Member of the Academy of Sciences of the U.S.S.R.

$\mathrm{T}$ HE mechanical structural properties of solidselasticity, plasticity and strength-are of paramount importance in most branches of modern engineering. These properties, which are determined by molecular interaction, are usually investigated without resorting to advanced physical chemistry. However, the methods of physico-chemical investigation of the deformation of solids, with due recourse to the factor of the chemical composition of the surrounding medium, lead to new methods of controlling the mechanical properties of solids and to novel methods of their mechanical treatment.

* Summary of a report at a general meeting of the Academy of Sciences of the U.S.S.R. in July 1946.
The earlier investigations by the author and his associates have established the fact that the addition to the surrounding medium of small amounts of the so-called surface-active substances, the particles of which are adsorbed on solid surfaces, is capable of considerably lowering the resistance of a solid to stress.

These very general phenomena of facilitating strain and disintegration of solids by adsorption have been extensively utilized by the author and his co-workers, and afterwards by many other investigators, both in the Soviet Union and abroad in various practical fields. For example, they have been used to facilitate the boring of stable (hard) rocks, in various processes of disintegration of solids by milling, in cutting and pressure working of metals, etc. It is this phenomenon of adsorptional promotion of strain that largely accounts for the effect of cooling lubricants, in the absence of which some of the above processes become altogether impracticable. The theory of this phen. omenon must underlie any scientifically based selection of these lubricants.

During the Second World War, mainly in connexion with the application of these investigations to the machining of metals, we succeeded in elucidating to some extent the mechanism of the adsorptional promotion of strain and, at the same time, in discovering a number of new phenomena in this domain.

It was ascertained that these phenomena are associated with the penetration of surface-active substances into the depth of the strained solid along the surface of the wedge-shaped ultra-microscopic cracks which are developed in course of deformation. After unloading, that is, removal of the stress, the micro-cracks become closed again, the surface-active substances adsorbed on their inner surface are expelled by molecular cohesion and the original mechanical properties of the solid are restored.

The closing of the micro-cracks after unloading is a process involved not only in elastic but also in plastic deformations, with the sole difference that, after shear involving slippage, the closing of the cracks takes place at new points of their surfaces.

These investigations have led to the discovery of some new phenomena which have been described in the report referred to above, and partly demonstrated in a micro-cinematographic film. Special interest is presented by two effects resulting from the penetration of surface-active substances into the microcracks: the retarded elastic deformation in mica crystals and the structural changes on plastic deformation of metals.

When a sheet of mica is bent or stretched in absolutely dry air, the deformation occurs practically instantaneously as soon as the external force is applied, and disappears also instantaneously after removal of the stress when the latter is below the elastic limit. In the presence of moisture, however -in water vapour or when the erystal is wetted with water-a gradual increase of deformation on application of stress is observed and a gradual decrease on removal of the stress. On addition to the water of organic substances readily adsorbed on mica, for example, alcohols, this retardation is still further enhanced, and the time required for the deformation to attain its maximum or to disappear after unloading is a matter of some three days. Complete recovery is observed in the case of these phenomena.

So long ago as in the experiments of I. Obreimov on the cleaving of mica along the cleavage planes in 